Título artículo / Títol article:
Influence of Particle Size on the Drying Kinetics of Single Droplets Containing Mixtures of Nanoparticles and Microparticles: Modeling and Pilot-Scale Validation
Autores / Autors
Rosa Mondragón Cazorla, José Enrique Juliá Bolívar, Leonor Hernández López, Juan Carlos Jarque Fonfría

Revista:

Drying Technology: An International Journal, 2013, vol. 31, núm. 7

Versión / Versió:

Pre-print

Cita bibliográfica / Cita bibliogràfica (ISO 690):
MONDRAGÓN CAZORLA, Rosa ; JULIÁ BOLIVAR, José Enrique ; HERNÁNDEZ LÓPEZ, Leonor ; JARQUE FONFRÍA, Juan Carlos. Drying Technology: An International Journal, 2013, vol. 31, núm. 7, p. 759-768

http://hdl.handle.net/10234/93750 


\title{
Influence of the particle size on the drying kinetics of single droplets containing mixtures of nanoparticles and microparticles. Modeling and pilot-scaled validation.
}

\author{
Rosa Mondragón ${ }^{1}$, J. Enrique Juliá 2,*, Leonor Hernández ${ }^{2}$, Juan Carlos Jarque ${ }^{1}$ \\ ${ }^{1}$ Instituto de Tecnología Cerámica. Universitat Jaume I. \\ Campus de Riu Sec. 12071-Castellón de la Plana. Spain \\ ${ }^{2}$ Departamento de Ingeniería Mecánica y Construcción. Universitat Jaume I \\ Campus de Riu Sec. 12071-Castellón de la Plana. Spain
}

\footnotetext{
* Corresponding author. E-mail: bolivar@emc.uji.es. Tel: +34 964728138. Fax: +34 964728106
} 


\begin{abstract}
The particle size of the primary particles is an important parameter influencing the drying behavior of droplets. In this work the influence of the particle size on the drying kinetics and the grain properties has been analyzed for droplets containing silica, microparticles and their mixtures. The presence of microparticles has been found to increase the drying rate and the shrinkage of the droplet. The drying curves have been modeled using the REA model. Finally, different suspensions were dried in a pilotscaled spray dryer in order to prove the influence of the particle size obtained in the levitator tests.
\end{abstract}

Key words: Drying, droplets, nanoparticles, microparticles, acoustic levitator 


\section{Introduction}

In many industrial applications (detergents, food products, etc.) it is very important to control the drying behavior and the final microstructure of the powder obtained by spray drying [1]. This powder is usually the final product which must be optimal to ensure a correct further use. Depending on the final application, different microstructures and physical properties can be required: degree of hollowness, porosity, grain size, mechanical properties, etc.

One of the properties of the suspensions to be dried, which can be modified in order to improve the spray drying process, is the particle size of the raw materials. It is well known that the particle size distribution of the primary particles influences the packing of the particles and the viscosity of the suspension [2-4]. In mixtures of particles of different sizes, the final packing fraction depends on the absolute size of each sort of particle, the size ratio and the fraction of coarse and fine particles.

The drying behavior and the final properties of powders obtained from traditional slurries containing microparticles can be improved by adding nanoparticles, as this modifies the particle packing. In polydisperse suspensions, the packing fraction is increased as fine particles are added to the coarse particles, because the small ones can occupy the voids between the larger ones. The packing is improved up to a maximum packing fraction, when all the voids are filled. Further additions of solid force the coarse particles apart and the packing is no longer improved. The evolution of the viscosity with the fraction of fine or coarse particles, present an inverse trend to the evolution of the packing density. When the packing of particles is increased, voids are removed and fine particles act as lubricant for the coarse particles, reducing the viscosities of the suspensions. 
The influence of the particle size on the drying kinetics can be explained through the Peclet number, $P e$, which characterizes the relative importance of the time scale for diffusion $\left(r_{d}{ }^{2} / D_{S}\right)$ with respect to that of the convective drying time $(t)$ [5-7]:

$P e=\frac{r_{d}^{2} / D_{S}}{t}$

The diffusion coefficient, $D_{S}$, can be calculated from the Einstein-Stokes relation:

$$
D_{S}=\frac{k_{B} \cdot T_{d}}{6 \cdot \pi \cdot \eta \cdot r_{p}}
$$

Low Peclet values are achieved when the particles diffuse easily or the drying time is long enough for the particles to diffuse toward the centre of the droplet during the first drying period. In these cases, the droplet surface is maintained saturated for a longer period of time, and consequently, the first drying period is longer, the critical moisture content (onset of second drying period) is lower, the shrinkage of the droplet is higher and the final grain diameter is smaller. On the contrary, for high Peclet values, the particles are not able to diffuse and the shell is formed earlier in the drying process. Droplets result in bigger grains, higher critical moisture content and shorter first drying period. In this case, more liquid is evaporated during the second drying period, in which the drying rate is slower and hence, the complete drying process becomes slower.

The decrease of the viscosity when the packing of the particles is increased leads to a faster diffusion of the particles and Peclet values lower than for monomodal solids. Therefore, the modification of this variable can significantly affect the process as mentioned above. As a result of introducing nanoparticles into a microparticle slurry, the drying is faster and the grain size is smaller. 
Previous studies have shown the influence of the primary particle size on the porosity and microstructure of the grains [8-10]. However, the mixtures were composed of different microparticles or nanoparticles, but no mixtures of both sorts of particles. Moreover, the drying curves were not obtained and any mathematical model was used to model the drying kinetics. In this way, modeling the drying kinetics is of great interest to predict the influence of the variables involved in the process on the drying behavior and on the final grain properties.

In last years, drying models based on the Reaction Engineering Approach (REA) have been successfully used to model the drying kinetics of different materials dried under different experimental conditions. The main theory of the model considers the drying as an activation process in which an energy barrier has to be overcome for moisture removal to occur. In the mathematical expression of the model, the vapor concentration gradient is considered the driving force of the drying. The water removal process is represented by an activation energy which value is zero when the solid is fully covered by water, and increases as the moisture content decreases, due to the difficulty of the water removal for low contents. Authors have found this model promising due to its simplicity and its high accuracy at different drying conditions. Putranto et al. [34, 35] applied the model to roasting of barley and coffee, drying of grains of food products (rice, maize...) and fruit tissues under constant and intermittent drying, and drying of biomaterials. The reaction engineering approach model has been also successfully used to model the drying kinetics of thin and thick layers of food materials with accuracy $[20,36]$. Finally, the model has been used to to predict the drying kinetics of droplets of different liquids and suspensions (skim milk, whole milk, lactose, proteins, sucrose, maltodextrin, glucose, silica nanofluids) [11-19, 37]. In all cases, the correlations needed for the activation energy were obtained so the 
mathematical model for the drying curve could be used to perform CFD simulations. In 2011, Zhu et al., [38] combined the drying-by-desorption method and the REA method in order to estimate the drying kinetics of skim milk droplets and predict gas-feed parameters in a pilot-scales spray dryer.

However, in all the previous works mentioned above the experimental data for the drying of single droplets were obtained by means of the glass filament method. This method has the disadvantage that the droplet is in contact with the filament and it is not completely isolated. In the last decade acoustic levitators has been extensively used to study the drying behavior of pure liquids, multi-component liquids and liquid-solid suspension droplets $[19,21-28]$ since there is no mechanical contact with the droplet, do not require any specific physical properties of the sample and provides stable sample position, easy access to the sample and low costs for supply and operation [29].

In a previous work the influence of the drying conditions on the final grain diameter and the internal microstructure of nanostructured grains was studied [39]. In that work authors found that the packing fraction of the particles inside the shell is constant but the shell thickness and the degree of hollowness of the grains denpend on the drying conditions and the grain diameter, which can be calculated from the critical moisture content.

In this work single droplets were dried in an acoustic levitator. The drying behavior of droplets of suspensions containing nanoparticles (fine), microparticles (coarse) and their mixtures was studied. Four different volumetric fractions for the coarse particles were studied: $x_{C}=0,0.40,0.85,1$. Moreover, the $p H$ of the suspensions was modified $(p H=2,10)$ and two initial droplet volumes were analyzed $\left(V_{0}=0.3,0.8\right.$ $\mu \mathrm{l})$. The drying curves $(X=\mathrm{f}(\mathrm{t}))$ were experimentally obtained for each test conducted and the REA model was used to model the experimental data. The influence of the 
volumetric fraction of coarse particles on the activation energy was also obtained. The evolution of the final grain diameter with the coarse fraction was also obtained and compared with theoretical values previously calculated. To check the applicability of the results obtained in the levitator, three different compositions were dried in a pilotscaled spray drier. The powders obtained were characterized in terms of particle size distribution, final moisture content and microstructure.

\section{Experimental set-up and measurement techniques}

\subsection{Drying of single droplets}

Single droplets were dried in an acoustic levitator. The experimental set-up and the operational conditions were described in detail in a previous work [25]. An acoustic levitator consisting of an ultrasonic $58 \mathrm{kHz}$ horn and a concave reflector (tec5 AG Sensorik und Systemtechnik) was used.

All the drying process was recorded and the images were processed with Matlab, so that the equivalent diameter and the position of the droplet during the drying process could be obtained. This information was used to calculate the mass transfer rate of the two drying periods and the moisture content at each time of the process.

In order to calculate the mass transfer rates, equations 3 to 5 were derived from the work by Kastner et al. [23]. The instantaneous mass transfer rate for the first drying period $\left(m_{L, 1}\right)$ is calculated by the decrease of the droplet volume. This mass transfer rate is defined as,

$m_{L, 1}=-\frac{\pi}{6} \rho_{L} \frac{d_{1}^{3}-d_{2}^{3}}{t_{1}-t_{2}}$

where the sub-indexes 1 and 2 denote two consecutive instants during the drying process. 
The mass transfer rate of the second drying period $\left(m_{L, 2}\right)$ is calculated using the position of the droplet inside the acoustic field:

$m_{L, 2}=\frac{M_{21}}{t-t_{21}} \frac{y(t)-y_{21}}{y_{22}-y_{21}}$

where $y_{21}$ and $y_{22}$ are the droplet positions at the beginning and the end of the second drying period respectively, $y(t)$ is the instantaneous position of the droplet, and $M_{21}$ is the liquid mass content in the droplet at the end of the first drying period previous to the shell formation.

With the initial water content and the liquid evaporation rates, the quantity of water present in the droplet/grain at each moment, can be easily calculated. The dry basis moisture, $X$, is defined as the ratio between the water and solid contents:

$$
X=\frac{M_{L}(t)}{M_{S}}
$$

\subsection{Spray drying}

Suspensions were dried in a pilot-scaled spray drier Mobile Minor (GEA Niro, Denmark). The suspension was atomized using a two-fluid nozzle (1.5 $\mathrm{mm}$ of inner diameter) located in the cone of the drying chamber, spraying upwards. Atomization is created by compressed air at a pressure of 1.4 bar. The drying air is introduced at $340^{\circ} \mathrm{C}$ in the centre of the chamber roof, being the outlet temperature of $110^{\circ} \mathrm{C}$. This sort of dryer, also known as mixed-flow dryer, combines counter-current and co-current layouts and ensures a longer residence time of the droplets inside the dryer.

After leaving the drying chamber, the air passes through a cyclone where the finest powder is retained. Both materials were collected, the coarse powder obtained at the bottom of the cone and the fine powder retained in the cyclone. 


\subsection{Characterization of the spray dried powder}

The powder obtained from the spray drying tests carried out in the pilot-scaled spray drier, was characterized in order to obtain its final properties.

The grain size distribution was measured using a Mastersizer 2000 (Malvern Instruments Ltd., UK). The spray dried powder was dry dispersed, and the laser light scattering principle was used to determine the size distribution.

The moisture content of the powder was measured using a thermobalance (Mettler Toledo SAE, Spain) which determines the percentage of water present in the sample analyzed.

Finally, the powders were observed by means of Scattering Electron Microscopy (SEM) using a Leica-Zeiss LEO 440 microscope. Powders were embedded in a resin and the surface was then polished to better observe the internal microstructure and the morphology of the grains.

\section{Materials and suspensions}

All the experiments were carried out with silica-water suspensions. Two sorts of particles, different in size, were used. For the nanoparticles, commercial fumed silica provided by Degussa was used. The chosen silica was Aerosil 200, which consists of amorphous hydrophilic silica nanoparticles with primary units of $12 \mathrm{~nm}$, which form agglomerates with a median particle size of $181 \mathrm{~nm}$ measured by DLS as can be observed in Figure 1.

The microparticles used in this work were purchased from Sigma-Aldrich. The median particle size measured by laser light scattering was $2.81 \mu \mathrm{m}$, but the particle size range varied from $0.5 \mu \mathrm{m}$ to $10 \mu \mathrm{m}$, as can be also observed in Figure 1 . In Figure 2 
micrographs of both materials taken by SEM are shown, so the differences in size and shape can be seen.

The procedure to prepare the suspensions depends on the amount of fluid required. For the drying tests in the levitator, small quantities are needed. In this case, the suspensions were prepared by adding the defined amounts of solids to distilled water. The dispersion was made using an ultrasonic probe (UP400s from Hielscher Company) that has been checked to be the most effective dispersion system [30]. In the cases in which pure components were used (either nanoparticles or microparticles) the suspension was submitted to a sonication treatment for 3 minutes. Afterwards, the $p H$ of the suspension was modified by adding $\mathrm{HCl}$ or $\mathrm{NaOH}$ solutions $(2.75 \mathrm{M})$. For the suspensions containing mixtures of nanoparticles and microparticles, first the nanoparticles were dispersed in water and an additional sonication treatment ( 2 minutes) was applied before the introduction of the microparticles. Then, the mixture was sonicated and the $p H$ was modified. Finally, after adjusting the $p H$ to ensure a correct dispersion of all the components, the suspensions were submitted to another sonication treatment during 2 minutes.

For the spray drying of suspensions, higher amounts of suspension were needed. In order to simplify the process all the components in the suspension were put together and stirred using a mechanical stirrer. When all the solids were completely wetted by the liquid and the mixture was homogeneous, a sonication treatment was applied for 10 minutes to disperse the agglomerates. Finally, the $p H$ of the medium was modified and the suspension was stirred again. 


\section{Results and discussion}

\subsection{Drying of single droplets}

Single droplets of silica-water suspensions containing nanoparticles $\left(x_{C}=0\right)$, microparticles $\left(x_{C}=1\right)$ and their mixtures $\left(x_{C}=0.40\right.$ and $\left.x_{C}=0.85\right)$ were dried at $120^{\circ} \mathrm{C}$. The suspensions tested contained a $20 \%$ wt. of solid content and two different $p H$ values were studied ( $p H=2$ and $p H=10)$. Moreover, the initial droplet volume was modified and droplets with two different volumes were dried $\left(V_{0}=0.3 \mu \mathrm{l}\right.$ and $\left.V_{0}=0.8 \mu \mathrm{l}\right)$.

For each experiment carried out, the evolution of the squared-diameter and the position of the droplet were obtained from the processing of the images recorded. Equations 3 to 8 were used to calculate the moisture content at any time of the drying process and hence, the drying curves. Figure 3 shows the drying curves obtained for each experimental condition. It can be observed that for small droplets $\left(V_{0}=0.3 \mu 1\right)$ the drying behavior is modified by the presence of particles different in size (Figure 3 (a) and 3 (b)). The suspensions containing only nanoparticles, form agglomerates that provide looser packing and higher viscosities, as can be seen in Table 1. The higher the viscosity of the liquid medium, the lower the diffusion coefficient. That means that the diffusion of the particles towards the inner part of the droplet is more complicated and therefore, the collapse of the particles and the formation of the shell occurs earlier in the drying process. The first drying period is shorter and the most part of the water content is removed during the second drying period through the pores of the shell. Consequently, the contraction of the droplet is lower and the drying process is slower.

When microparticles are added to the suspension, the packing of the particles increases and the viscosity decreases. As a result of the lower viscosity, the particles can diffuse faster towards the centre of the droplet, allowing the saturation of the droplet 
surface during a longer period of time. Therefore, as the fraction of coarse particles increases, the duration of the first drying period also does and the droplet dries earlier. The contraction of the droplet increases too and the final grain size is smaller, as can be observed in Figure 4.

The packing of the particles increases up to reach a maximum value and then, further additions of microparticles lead to a reduction in the packing fraction. The packing fraction for microparticle suspensions $\left(x_{C}=1\right)$ is lower than for $x_{C}=0.85$ but higher than for the nanoparticle suspension $\left(x_{C}=0\right)$. These intermediate conditions also provides intermediate viscosities and the drying behavior is between the two extreme $\operatorname{cases}\left(x_{C}=0\right.$ and $\left.x_{C}=0.85\right)$.

However, the fraction of coarse particles does not influence the drying process for big size droplets $\left(V_{0}=0.8 \mu \mathrm{l}\right)$ (Figure 3 (c) and 3 (d)). In these cases, it seems that the droplet volume slows down the drying process so that the particles can diffuse inside the droplet independently of the diffusion coefficient.

\section{Application of REA model}

The drying curves obtained (Figure 3) were modeled using the REA model, which was previously used to model the drying kinetics of nanoparticle suspensions providing good results [20]:

$$
\frac{d X}{d t}=-\frac{h_{m} A}{M_{S}}\left[\rho_{v, s a t} \exp \left(-\frac{\Delta E_{V}}{R T_{d}}\right)-\rho_{v, a}\right]
$$

The acoustic field inside the acoustic levitator, results in an acoustic stream that provides a drying mechanism stronger than the natural convection and dominates the process [31]. In consequence, the available correlation provided by Ranz and Marshall in $1952[32,33]$ for the Sherwood number cannot be used and the mass transfer 
coefficients, $h_{m}$, must be experimentally determined under the corresponding drying conditions. This coefficient depends on the temperature and droplet volume. So, for each droplet volume, the mass transfer coefficient was obtained at the drying temperature, from the drying of pure liquid droplets by means of the mass conservation equation. For $V_{0}=0.3 \mu$, the mass transfer coefficient resulted in $h_{m}=0.0798 \mathrm{~m} / \mathrm{s}$, whereas for $V_{0}=0.8 \mu 1$, the mass transfer coefficient resulted in $h_{m}=0.0796 \mathrm{~m} / \mathrm{s}$. More details can be found in Mondragon et al. [20].

The temperature of the droplet can be considered uniform through the droplet for Biot numbers less than 0.1 [13]. In this work, the value of this parameter is less than 0.07 for all tests and therefore and the droplet temperature could be considered uniform. The evolution of the droplet temperature was calculated by means of the energy balance equation with the help of the experimental data obtained for the drying curves.

$$
m_{d} C_{p, d} \frac{d T_{d}}{d t}=h_{C} A\left(T-T_{d}\right)+\Delta H_{v} \frac{d m_{L}}{d t}
$$

were $m_{d}$ is the overall mass of the droplet, $C_{p . d}$ is the specific heat capacity of the droplet, $h_{C}$ is the heat transfer coefficient, $\Delta H_{\mathrm{v}}$ is the latent heat of water evaporation and $d m_{d} / d t$ is the change of liquid content inside the droplet during the drying process.

In Figure 5 the evolution of the droplet temperature during the drying process is plotted together with the corresponding drying curve for one of the tests carried out. It can be observed that during the first drying period the droplet temperature remains constant and equal to the wet bulb temperature. During the second drying period the droplet temperature increases up to the drying air temperature.

The activation energy, which depends on the material and the drying conditions, can be fitted to the expression: 


$$
\Delta E_{V}=a \exp \left[-b\left(X-X_{e q}\right)^{c}\right]
$$

where parameter $a$ was found to be constant, while parameters $b$ and $c$ depended on the solid content, $Y_{S}$, and the air temperature, $T$, for a specific material.

In the previous work carried out the parameters of the activation energy were established for the silica-water nanoparticle system. Parameter $a$ was found to be constant, $a=3.15 \cdot 10^{7}$, parameter $c$ was found to depend on the solid content, $c=0.735-1.178 \cdot 10^{-3} Y_{S}^{-1.582}$, and parameter $b$ was found to depend on the solid content and the air temperature, $b=1,217+29.193 Y_{S}+9.233 \cdot 10^{-3} T-0.250 Y_{S} T$.

In this work, as the solid content and the drying temperature were kept constant, parameters $a$ and $c$, were found to be constant. However, parameter $b$ depended on the fraction of the coarse particles and the droplet volume, as can be seen in Figure 6. As mentioned before, the drying behavior for big droplets, is not influenced by the coarse fraction and therefore the $b$ parameter was also found independent of it. For smaller droplets, the $b$ parameter depended on the coarse fraction and its evolution is the same that found for the packing fraction [2]: increases as the coarse fraction increases up to a maximum value and then decreases, being the value for full microparticles intermediate between $x_{C}=0$ and $x_{C}=0.85$. Comparing with the drying curves, it can be conclude that the higher the value of $b$, the longer the first drying period and the higher the contraction of the droplet. As it can be seen in the results, the influence of the $p H$ was negligible. Just for the suspensions containing only nanoparticles, the $p H$ value modifies the viscosity due to the change in the surface forces acting on the particles, and at $p H=2$ (there is no electrostatic repulsion), the lower viscosity makes slightly easier the diffusion of the particles. However, the influence for the droplet volume range analyzed 
in this work can not be considered of importance. In Table 2 the values for the $b$ parameter for each coarse fraction and droplet volume are given.

Once the drying kinetics has been modeled, the final grain diameter can easily be obtained from the drying curves. This variable is related to the critical moisture content, $X_{c r}$, by the following equation previously applied to the drying of different materials $[39,40]$ :

$$
d_{G}=d_{c r}=d_{0, d} \cdot \sqrt[3]{\frac{\rho_{L}+X_{c r} \cdot \rho_{S}}{\rho_{L}+X_{0} \cdot \rho_{S}}}
$$

where $d_{c r}$ is the critical diameter equal to the final grain diameter (the shrinkage of the droplet stops at the critical moisture content), $d_{0, d}$ is the initial droplet diameter, $X_{0}$ is the initial moisture content and $\rho_{L}$ and $\rho_{S}$ are the densities of the liquid and the solid respectively.

That critical moisture content, $X_{c r}$, represents the beginning of the second drying period and can be obtained from the drying kinetics of a single droplet. From the drying test, and the evolution of the droplet diameter and position recorded and processed, the critical moisture content was obtained for each experimental condition. The final grain diameter was calculated by means of equation 9. Figure 7 shows the good agreement between the theoretical values and the experimental values obtained from the image processing, confirming that the equation is still valid for any sort of material being dried.

\subsection{Spray drying}

The results obtained from the drying of single droplets in the acoustic levitator were checked by drying suspensions in a pilot-scaled spray drier. The three suspensions 
chosen to spray dry, namely hereinafter 1,2 and 3 , were: 1) $x_{C}=0$ and $\left.p H=10 ; 2\right) x_{C}=$ 0 and $p H=2$; and 3) $x_{C}=0.85$ and $p H=10$.

Figure 8 shows the drying curves of the three chosen suspensions, previously obtained in the drying tests of small single droplets $\left(V_{0}=0.3 \mu \mathrm{l}\right)$ in the acoustic levitator. Although the natural convection inside the spray dryer provides higher mass transfer coefficients and faster drying, the drying behavior and the influence of the variables must be the same that found in the levitator tube. On the other hand, the nozzle of the spray dryer generates a spray of droplets with a smaller droplet size than those tested in the levitator. All these factors promote a faster drying that makes more important the diffusion time of the particles inside the droplets, and therefore the influence of the input variables on the final powder properties is enhanced. From the curves in Figure 8, it was expected that, if the residence time of the droplet inside the dryer is constant, the moisture content of powder 1 must be higher than that of powder 2 and both higher than the moisture of powder 3. Besides, and according to the duration of the first drying period and the contraction of the droplet, the particle size was expected to be the highest for suspension 1 and the smallest for suspension 3 .

Both the coarse powder obtained at the bottom of the dryer and the fine powder obtained at the end of the cyclone were collected for each of the three suspensions. The droplet size distribution within the spray is wide and leads to a particle size distributions which finest particles are easily kept within the cyclone and never fall to the bottom. The mass fraction of coarse $\left(w_{C}\right)$ and fine $\left(w_{F}\right)$ solids collected were calculated and are shown in Table 3. It can be observed that no significant difference for suspensions 1 and 2 in the amount of coarse and fine grains was found. Although the drying curves were different for these two suspensions, and the corresponding particle sizes were also expected to differ, the powders was still coarse enough to be collected at the bottom of 
the dryer in the same proportions. However, for suspension 3 the contraction of the droplets was so high that most of the powder was collected at the cyclone and only a little amount fell down the dryer.

In Table 3 it can also be seen the final moisture content of the obtained powders. For both, the fine and the coarse powder, powder 1 is wetter than powder 2 and wetter than powder 3, confirming the trend obtained in the levitator tests.

Due to the so small grain size of the fine powder, which resulted in intangible powder, the next analyses were only performed with the coarse powders. The grain size distributions were measured for powders 1, 2 and 3 are plotted in Figure 9. The median grain size, $d_{G, 50}$, of the powders is shown in Table 3. As expected, the smallest grain size is obtained when a mixture of nanoparticles and microparticles is used confirming the trend obtained in the levitator tests.

Finally, the internal microstructure and the morphology of the coarse powders obtained from the drying of the three suspensions were observed by means of SEM. In Figure 10 the observed micrographs can be seen. In these images the evolution of the grain size with the $\mathrm{pH}$ and the coarse fraction can also be observed. As obtained for the grain size distributions, the grain size decreases at $\mathrm{pH}=2$ due to the lower viscosity and the faster diffusion of the particles. Besides, the smallest grains were obtained from the mixture of nanoparticles and microparticles. Regarding the microstructure, when microparticles were added, the highest particle packing achieved produced grains with smaller shell thickness. For grains with the same final diameter, that means that the hollowness of the grain is higher as can be observed in the grains identified in the micrographs. Moreover, suspension 3 led to a powder with grains more irregular in shape. The presence of particles with different size produces a more heterogeneous 
surface of the shell and leads to a different magnitude of the capillary forces acting on the particles. As a result the shrinkage of the droplet was more irregular.

\section{Conclusions}

The influence of the particle size of the primary particles on the drying kinetics of silica-water single droplets was analyzed. Droplets containing nanoparticles, microparticles and mixtures were dried at $120^{\circ} \mathrm{C}$ under different experimental conditions of $\mathrm{pH}$ and droplet volume.

For bigger droplets $\left(V_{0}=0.8 \mu \mathrm{l}\right)$ the particle size did not influence the drying kinetics due to the slower drying that provides enough time to the particles to diffuse inside the droplets independently of the diffusion rate. For smaller droplets $\left(V_{0}=0.3 \mu \mathrm{l}\right)$ the drying behavior depended on the particle size. The slowest drying was provided by the nanoparticle suspension, which presented the looser packing. As long as the packing of the particles was improved by addition of microparticles, the viscosity decreased and the particles could diffuse more easily leading to a higher contraction of the droplets and a shorter drying. The two limit cases were the nanoparticle case $\left(x_{C}=0\right)$ and the mixture that provided the best packing $\left(x_{C}=0.85\right)$.

The drying curves were modeled using the REA model. In the activation energy only the parameter $b$ depended on the particle size for small droplets. The trend was the same followed by the packing fraction. The lowest value was obtained for the nanoparticle system, while its value was increased when microparticles were added to the suspension, increasing the particle packing. The maximum value was achieved at $x_{C}$ $=0.85$, and further additions of coarse solid decreased the packing fraction and the $b$ parameter. 
In order to validate the results obtained in the acoustic levitator, three different suspensions were dried in a pilot-scaled spray dryer. The results obtained in both cases showed a good agreement. The suspension prepared at $x_{C}=0.85$ generated the powder with the lowest moisture content and the smallest grain size, confirming the trend obtained in the levitator tests. This means that single droplet tests could be used to simulate the drying behavior of spray died droplets and to predict the final properties of the grains.

\section{Acknowledgments}

R. Mondragón thanks the Spanish Ministry of Education for a pre-doctoral fellowship (FPU program, Ref. AP2008-01077).

\section{Nomenclature}

$\begin{array}{ll}A & \text { droplet surface area }\left[\mathrm{m}^{2}\right] \\ d & \text { droplet diameter }[\mathrm{m}] \\ D & \text { diffusion coefficient }\left[\mathrm{m}^{2} / \mathrm{s}\right] \\ h_{m} & \text { mass transfer coefficient }[\mathrm{m} / \mathrm{s}] \\ k_{B} & \text { Boltzman constant } \\ m & \text { mass transfer rate }[\mathrm{kg} / \mathrm{s}] \\ M & \text { mass of component }[\mathrm{kg}] \\ r & \text { radius [m] } \\ R & \text { gas constant }[\mathrm{J} / \mathrm{mol} \cdot \mathrm{K}] \\ T & \text { temperature }\left[{ }^{\circ} \mathrm{C}\right] \\ t & \text { drying time }[\mathrm{s}] \\ V & \text { volume }\left[\mathrm{m}^{3}\right] \\ w & \text { mass fraction }[\mathrm{kg} \mathrm{solid} / \mathrm{kg} \text { total }] \\ X & \text { dry basis moisture content }[\mathrm{kg} \text { water } / \mathrm{kg} \text { dry solid] } \\ x & \text { volumetric fraction }\left[\mathrm{m}^{3} \text { solid } / \mathrm{m}^{3} \text { total }\right] \\ y & \text { droplet position }[\mathrm{m}] \\ \Delta E_{V} & \text { activation energy }[\mathrm{J} / \mathrm{mol}]\end{array}$




$\begin{array}{ll}\eta & \text { viscosity }[\mathrm{kg} /(\mathrm{m} \cdot \mathrm{s})] \\ \rho & \text { density }\left[\mathrm{kg} / \mathrm{m}^{3}\right]\end{array}$

\section{Subscripts}

$\begin{array}{ll}a & \text { air } \\ C & \text { coarse } \\ d & \text { droplet } \\ e q & \text { equilibrium } \\ F & \text { fine } \\ G & \text { grain } \\ L & \text { liquid } \\ p & \text { particle } \\ S & \text { solid } \\ \text { sat } & \text { saturation } \\ \text { surf } & \text { surface } \\ \text { Sus } & \text { suspension } \\ v & \text { water vapor }\end{array}$




\section{References}

[1] Masters, K. Spray drying handbook; Longman Scientific and Technical, 1991.

[2] German, R.M. Particle Packing Characteristics; Metal Powder Industries Federation, Princeton, New Jersey, 1989.

[3] Zaman, A.A.; Moudgil, B.M. Role of electrostatic repulsion on the viscosity of bidisperse silica suspensions. Journal of Colloid and Interface Science 1999, $212,167-175$.

[4] Qin, K.; Zaman, A.A. Viscosity of concentrated colloidal suspensions: comparison of bidisperse models. Journal of Colloid and Interface Science 2003, $266,461-467$.

[5] Sen, D.; Spalla, O.; Tache, O.; Haltebourg, P.; Thill, A. Slow drying of a spray of nanoparticles dispersion. In situ SAXA investigation. Langmuir 2007, 23, 4296-4302.

[6] Sen, D.; Mazumder, S.; Melo, J.S.; Khan, A.; Bhattyacharya, S.; D’Souza, D.F. Evaporation driven self-assembly of a colloidal dispersion during spray drying: volume fraction dependent morphological transition. Langmuir 2009, 25, 66906695.

[7] Bahadur, J.; Sen, D.; Mazumder, S.; Paul, B.; Khan, A.; Ghosh, G. Evaporationinduced self assembly of nanoparticles in non-buckling regime: volume fraction dependent packing. Journal of Colloid and Interface Science 2010, 351, 357364.

[8] Mondragon, R.; Jarque, J.C.; Julia, J.E.; Hernandez, L.; Barba, A. Effect of slurry properties and operational conditions on the structure and properties of 
porcelain tile granules dried in an acoustic levitator. Journal of the European Ceramic Society 2012, 32, 59-70.

[9] Wang, A.J.; Lu, Y.P.; Sun, R.X. Recent progress on the fabrication of hollow microspheres. Materials Science and Engineering A 2007, 460-461.

[10] Kim, C.S.; Ahn, K.W.; Rah, S.C.; Kim, S.G. Preparation of silica nanostructured spheres by sol spray drying. Drying Technology 2008, 26, 260-264.

[11] Chen, X.D. The basics of a reaction engineering approach to modelling airdrying of small droplets or thin-layer materials. Drying Technology 2008, 26, 627-639.

[12] Chen, X.D.; Lin, S.X.Q. Air drying of milk droplet under constant and timedependent conditions. AIChE Journal 2005, 51, 1790-1799.

[13] Fu, N.; Woo, M.W.; Lin, S.X.Q.; Zhou, Z.; Chen, X.D. Reaction engineering approach (REA) to model the drying kinetics of droplets with different initial sizes-experiments and analyses. Chemical Engineering Science 2011, 66, 17381747.

[14] Lin, S.X.Q.; Chen, X.D. A model for drying and aqueous lactose droplet using the reaction engineering approach. Drying Technology 2006, 24, 1329-1334.

[15] Lin, S.X.Q.; Chen, X.D. The reaction engineering approach to modelling cream and whey protein concentrate droplet drying. Chemical Engineering and Processing 2007, 46, 437-443.

[16] Patel, K.C.; Chen, X.D. Prediction of spray-dried product quality using two simple drying kinetics models. Journal of Food Process Engineering 2005, 28, $567-594$. 
[17] Patel, K.C.; Chen, X.D.; Lin, S.X.Q. A composite reaction engineering approach to drying of aqueous droplets containing sucrose, maltodextrin (DE6) and their mixtures. AIChE Journal 2009, 55, 217-231.

[18] Woo, M.W.; Wan Daud, W.R.; Mujumdar, A.S.; Meor Talib, M.Z.; Hua, W.Z.; Tasirin, S.M. Comparative study of droplet drying models for CFD modelling. Chemical Engineering Research and Design 2008, 86, 1038-1048.

[19] Mondragon, R.; Julia, J.E.; Hernandez, L.; Jarque, J.C. Modelling of drying curves of silica nanofluid droplets dried in an acoustic levitator using the Reaction Engineering Approach (REA) model. Drying Technology 2012, accepted for publication.

[20] Chen, X.D.; Xie, G.Z. Fingerprints of the drying behavior of particulate or thin layer food materials established using a reaction engineering model. Food and Bioproduct Processes 1997, 75, 213-222.

[21] Brenn, G. Concentration fields in evaporating droplets. International Journal of Heat and Mass Transfer 2005, 48, 395-402.

[22] Brenn, G.; Kastner, O.; Rensink, D.; Tropea, C. Evaporation and drying of multicomponent and multiphase droplets in a tube levitator. In Proceedings of the $15^{\text {th }}$ Annual Conference on Liquid Atomization and Spray Systems (ILASS Europe), Toulouse, 1999.

[23] Kastner, O.; Brenn, G.; Rensink, D.; Tropea, C. Mass transfer from multiphase droplets during drying in a tube levitator. In Proceedings of the 8th International Conference on Liquid Atomization and Spray Systems, Pasadena, 2000. 
[24] Kastner, O.; Brenn, G.; Rensink, D.; Tropea, C. The acoustic tube levitator: a novel device for determining the drying kinetics of single droplets. Chemical Engineering Technology 2001, 24, 335-339.

[25] Mondragon, R.; Hernandez, L.; Julia, J.E.; Jarque, J.C.; Chiva, S.; Zaitone, B.; Tropea, C. Study of the drying behavior of high load multiphase droplets in an acoustic levitator at high temperature conditions. Chemical Engineering Science 2011, 66, 2734-2744.

[26] Yarin, A.L.; Brenn, G.; Kastner, O.; Rensink, D.; Tropea, C. Evaporation of acoustically levitated droplets. Journal of Fluid Mechanics 1999, 399, 151-204.

[27] Yarin, A.L.; Brenn, G.; Kastner, O.; Tropea, C. Drying of acoustically levitated droplets of liquid-solid suspensions: evaporation and crust formation. Physics of Fluids 2002, 14, 2289-2298.

[28] Zaitone, B.; Hunsmann, S.; Castanet, G.; Damaschke, N.; Ebert, V.; Tropea, C. Evaporation of acoustically levitated droplets. In Proceedings of the 10th International Congress on Liquid Atomization and Spray Systems, Kyoto, 2006.

[29] Omrane, A.; Santesson, S.; Alden, M.; Nilsson, S. Laser techniques in acoustically levitated micro droplets. Lab on a Chip - Miniaturisation for Chemistry and Biology 2004, 4, 287-291.

[30] Petzold, G.; Rojas-Reyna, R.; Mende, M.; Schwarz, S. Application relevant characterization of aqueous silica nanodispersions. Journal of Dispersion Science and Technology 2009, 30, 1216-1222.

[31] Kawahara, N.; Yarin, A.L.; Brenn, G.; Kastner, O.; Durst, F. Effect of acoustic streaming on the mass transfer of a sublimating sphere. Physic of Fluids 2000, $12,912-923$. 
[32] Ranz, W.E.; Marshall, J.R. Evaporation from drops 1. Chemical Engineering Progess 1952, 48, 141-146.

[33] Ranz, W.E.; Marshall, J.R. Evaporation from drops 2. Chemical Engineering Progess 1952, 48, 173-180.

[34] Putranto, A.; Chen, X.D. Roasting of Barley and Coffee Modeled Using the Lumped-Reaction Engineering Approach (L-REA). Drying Technology 2012, $30,475-483$.

[35] Putranto, A.; Chen, X.D.; Xiao, Z.; Webley, P.A. Simple, accurate and robust modeling of various systems of drying of foods and biomaterials: A demonstration of the feasibility of the reaction engineering approach (REA). Drying Technology 2011, 29, 1519-1528.

[36] Putranto, A.; Chen, X.D.; Webley, P.A. Modeling of drying of food materials with thickness of several centimeters by the reaction engineering approach (REA). Drying Technology 2011, 29, 961-973.

[37] Che, L.; Li, D.; Chen, X.D. Convective Drying Kinetics of Single Droplets of Aqueous Glucose. Drying Technology 2012, 30, 1029-1036.

[38] Zhu, P.; Patel, K.; Lin, S.; Méjean, S.; Blanchard, E.; Chen, X.D.; Schuck, P.; Jeantet, R. Simulating industrial spray-drying operations using a reaction engineering approach and a modified desorption method. Drying Technology 2011, 29, 419-428.

[39] Mondragon, R. ; Julia, J.E. ; Barba, A. ; Jarque, J.C. Microstructure and mechanical properties of grains of silica nanofluids dried in an acoustic levitator. Journal of the European Ceramic Society 2012, 32, 4295-4304. 
[40] Mezhericher, M.; Levy, A.; Borde, I. Theoretical drying model of single droplets containing insoluble or dissolved solids. Drying Technology 2007, 25, 10351042. 


\section{Figure captions}

Figure 1. Particle size distribution for silica nanoparticles and microparticles.

Figure 2. SEM micrographs of (a) silica nanoparticles and (b) silica microparticles.

Figure 3. Drying curves: experimental data and REA model. (a) $V_{0}=0.3 \mu 1, p H=2$, (b) $V_{0}=0.3 \mu 1, p H=10$, (c) $V_{0}=0.8 \mu 1, p H=2$, (d) $V_{0}=0.8 \mu 1, p H=10$.

Figure 4. Evolution of the grain diameter with coarse fraction and $\mathrm{pH}$ for small droplets.

Figure 5. Evolution of moisture content and droplet temperature for $Y_{S}=0.20, p H=10$, $T=120^{\circ} \mathrm{C}, V_{0}=0.8 \mu \mathrm{l}, x_{C}=0.85$.

Figure 6. Evolution of $b$ parameter with coarse fraction, droplet volume and $p H$.

Figure 7. Final grain diameter determined experimentally and theoretically.

Figure 8. Drying curves for the spray dried suspensions.

Figure 9. Grain size distributions for spray dried powders 1, 2 and 3.

Figure 10. SEM micrographs of powders (a) $1, x_{C}=0, p H=10$, (b) $2, x_{C}=0, p H=2$ and (c) $3, x_{C}=0.85, p H=10$. 


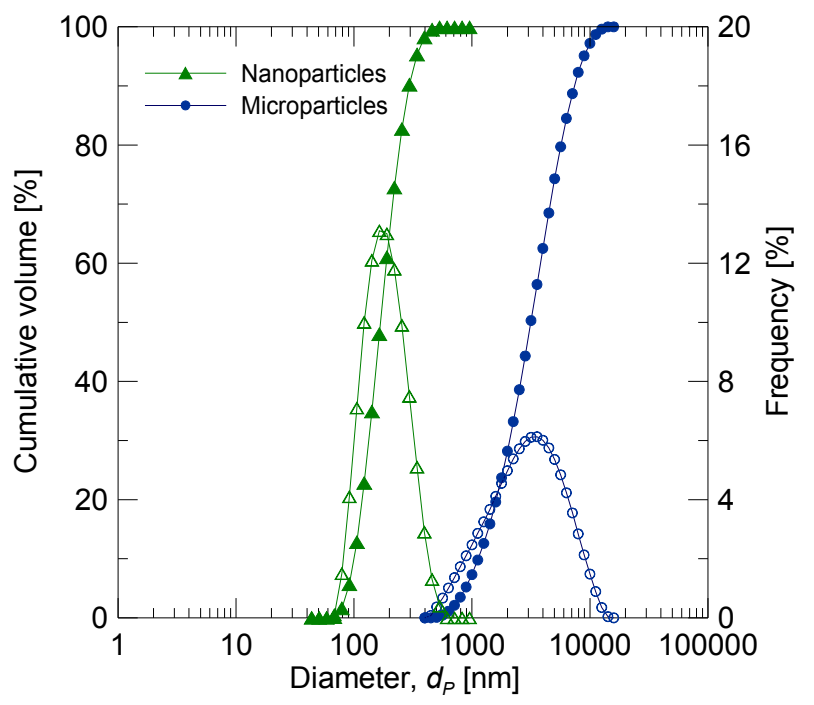

Figure 1. Particle size distribution for silica nanoparticles and microparticles. 


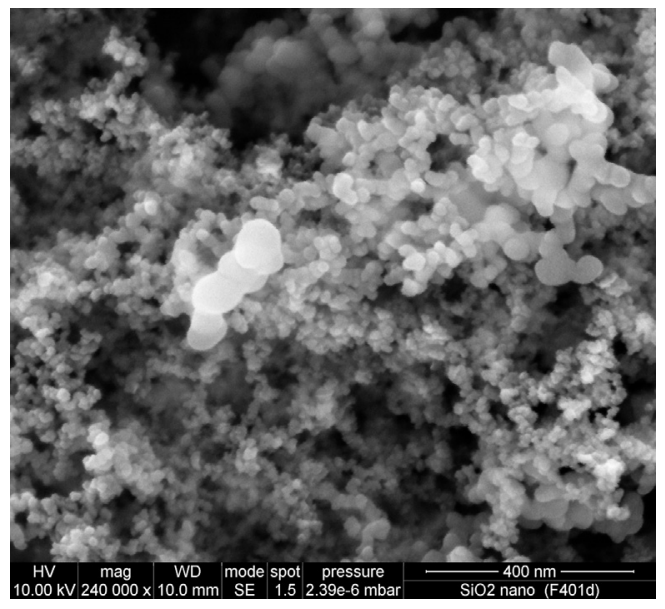

(a)

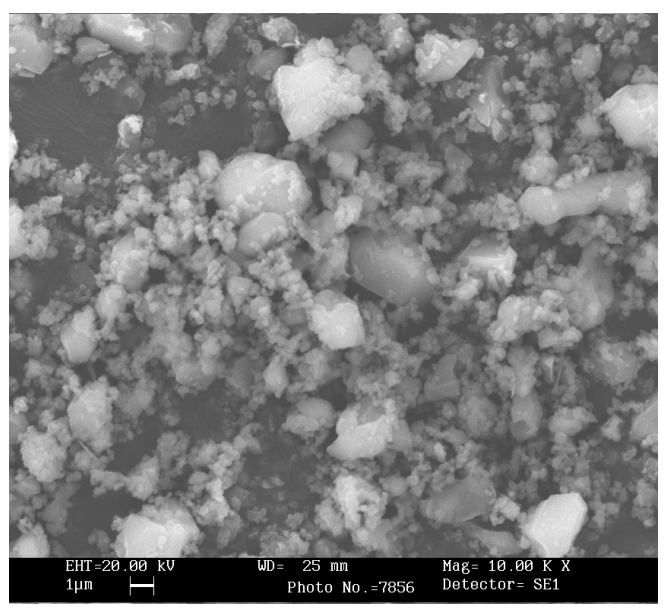

(b)

Figure 2. SEM micrographs of (a) silica nanoparticles and (b) silica microparticles. 


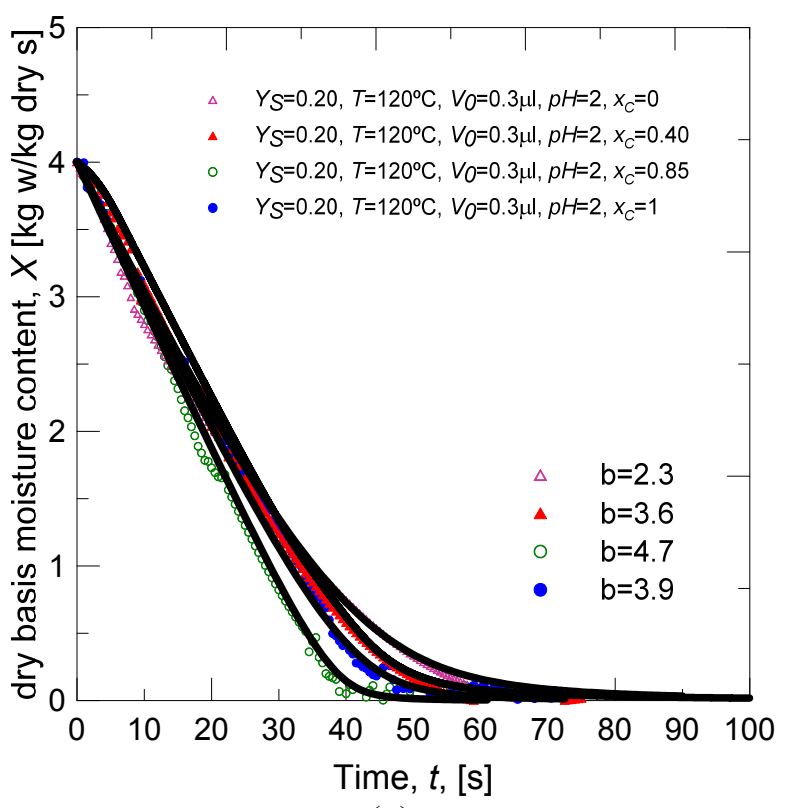

(a)

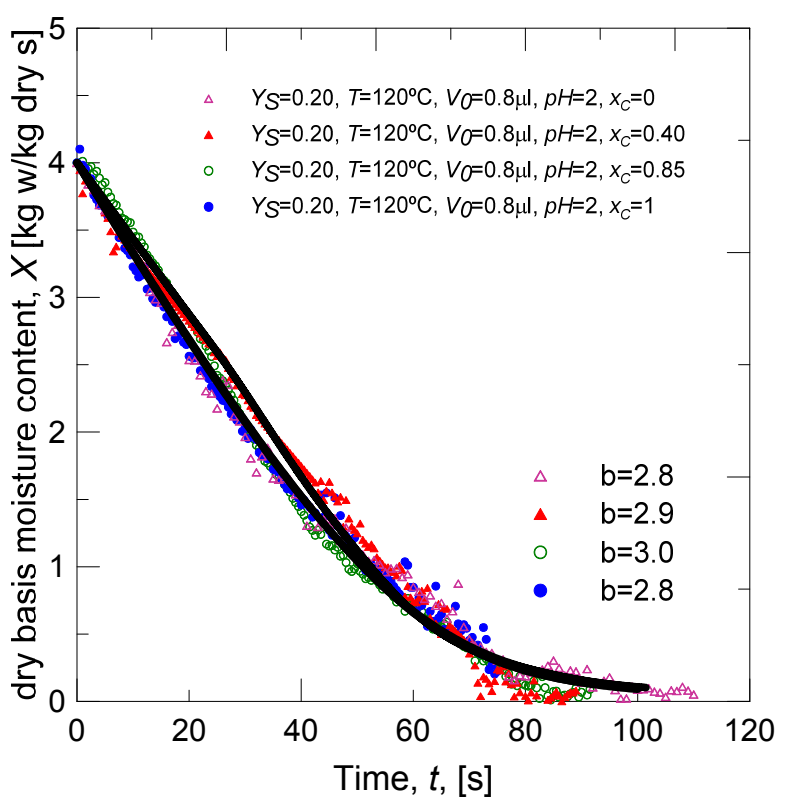

(c)

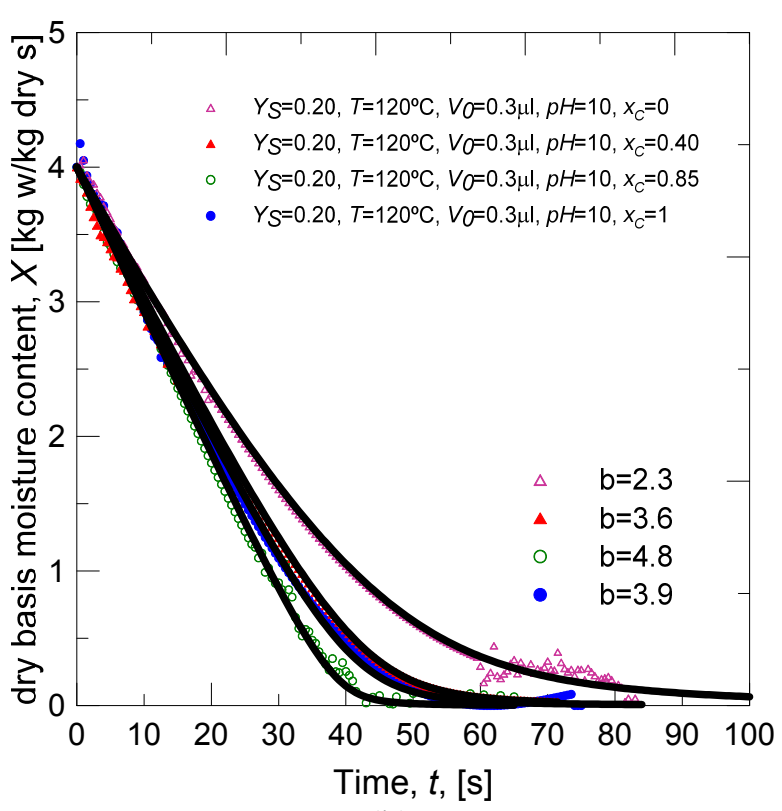

(b)

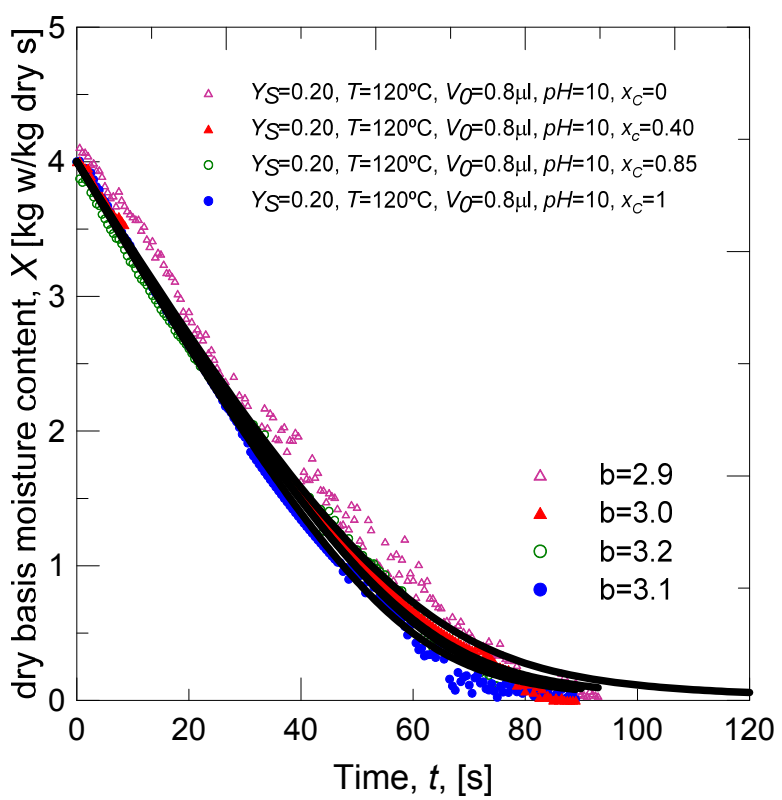

(d)

Figure 3. Drying curves: experimental data and REA model. (a) $V_{0}=0.3 \mu \mathrm{l}, p H=2$, (b) $V_{0}=0.3 \mu \mathrm{l}, p H=10$, (c) $V_{0}=0.8 \mu \mathrm{l}, p H=2$, (d) $V_{0}=0.8 \mu \mathrm{l}, p H=10$. 


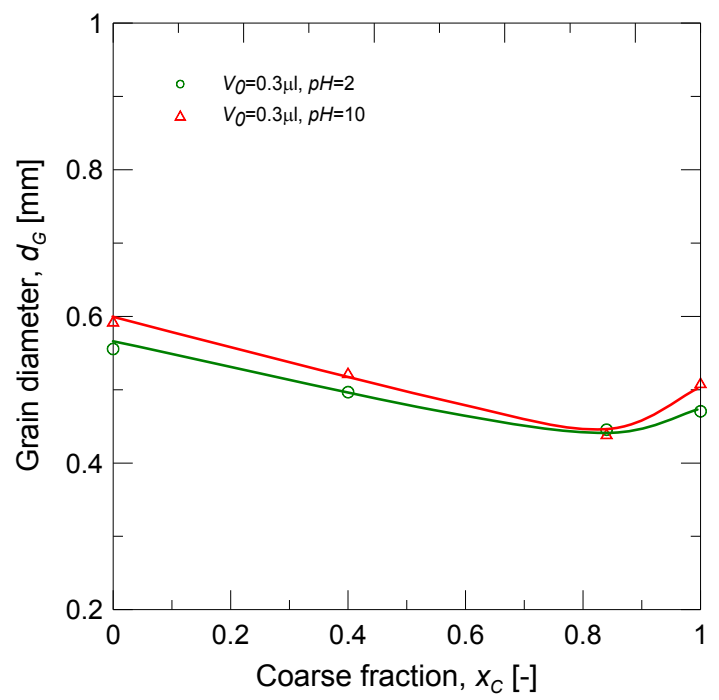

Figure 4. Evolution of the grain diameter with coarse fraction and $\mathrm{pH}$ for small droplets. 


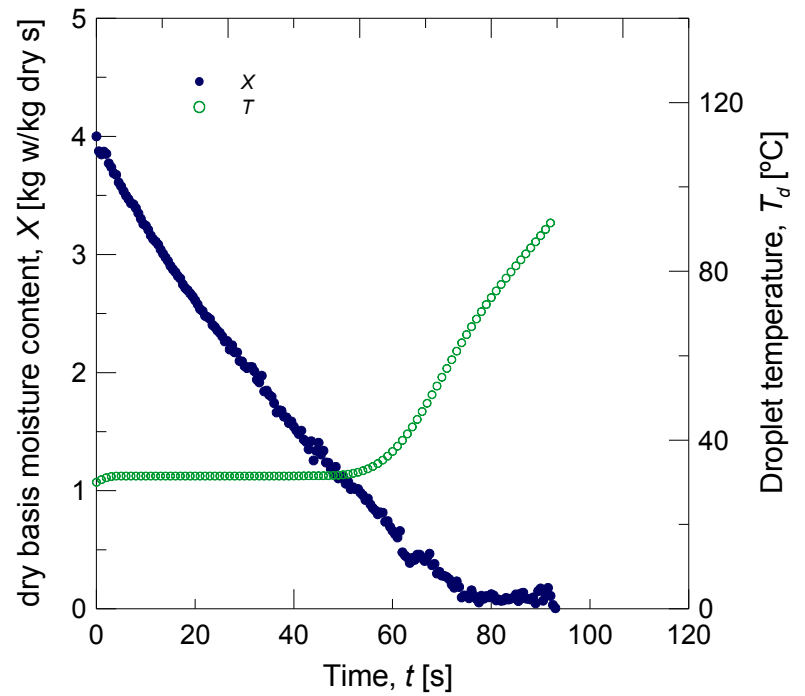

Figure 5. Evolution of moisture content and droplet temperature for $Y s=0.20$, $p H=10, T=120^{\circ} \mathrm{C}, V_{0}=0.8 \mu \mathrm{l}, x_{C}=0.85$. 


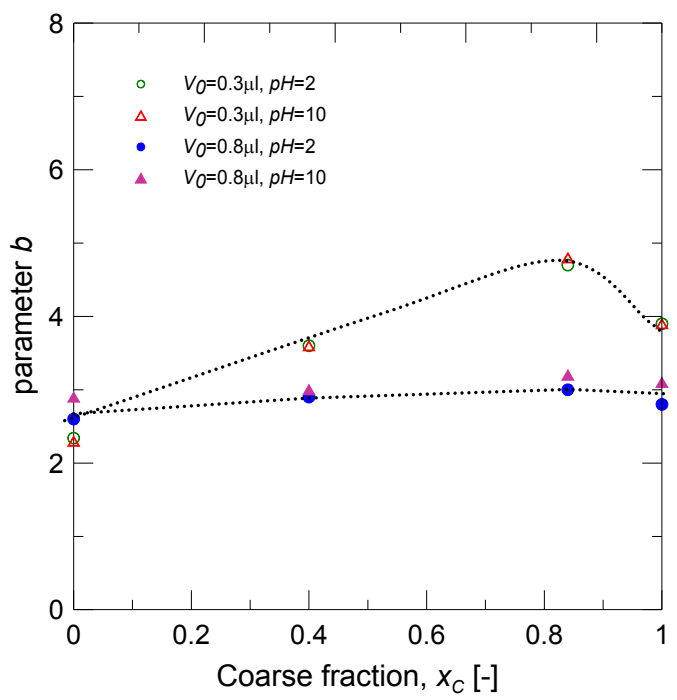

Figure 6. Evolution of $b$ parameter with coarse fraction, droplet volume and $p H$. 


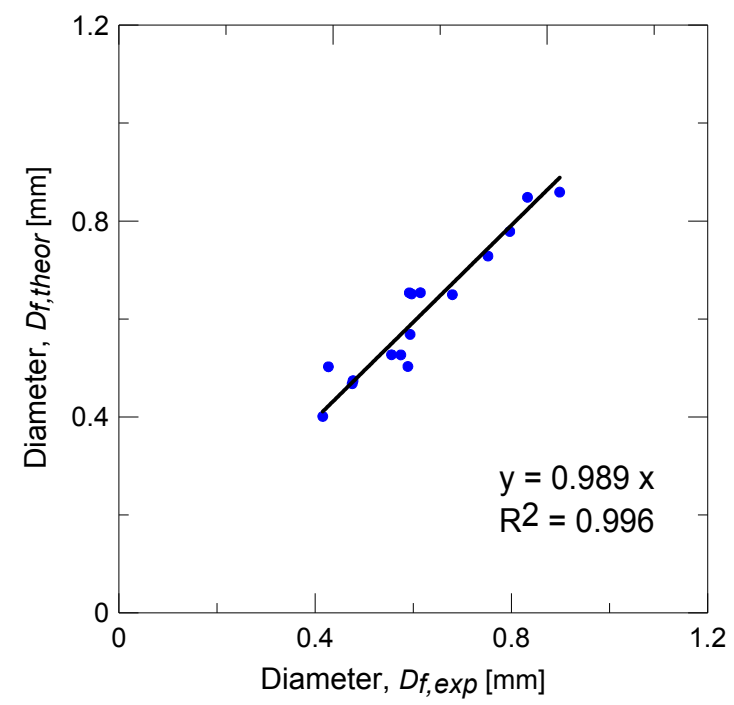

Figure 7. Final grain diameter determined experimentally and theoretically. 


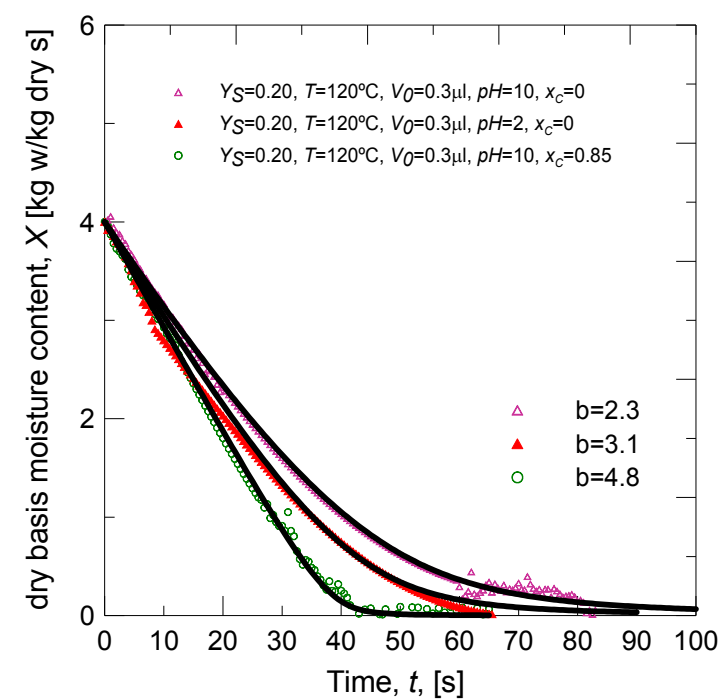

Figure 8. Drying curves for the spray dried suspensions. 


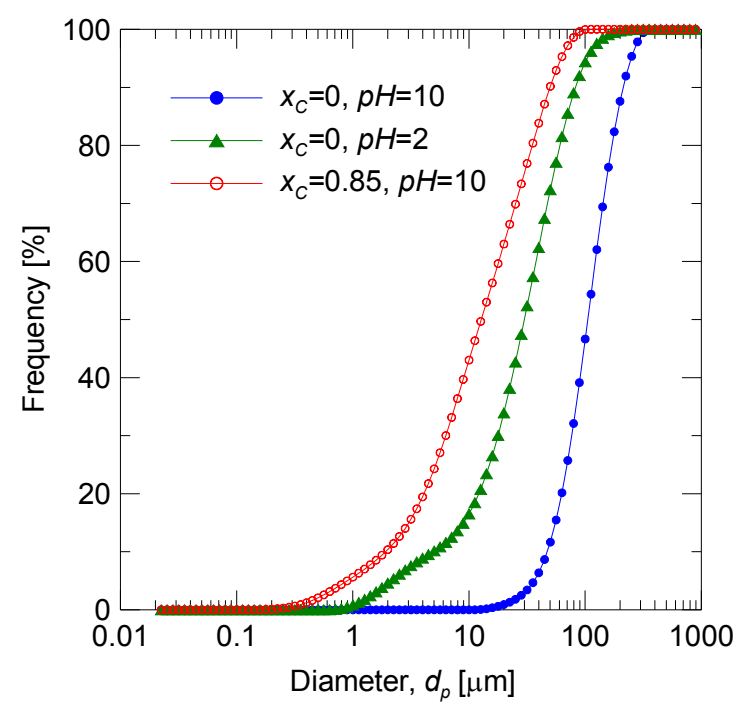

Figure 9. Grain size distributions for spray dried powders 1, 2 and 3. 

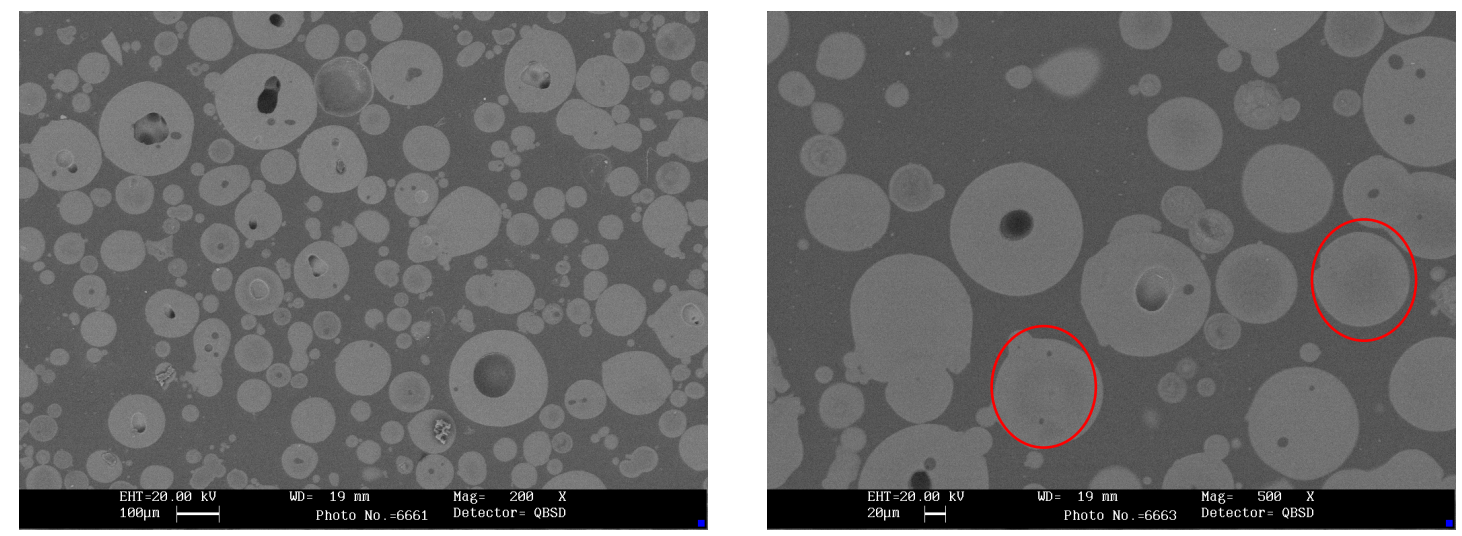

(a)
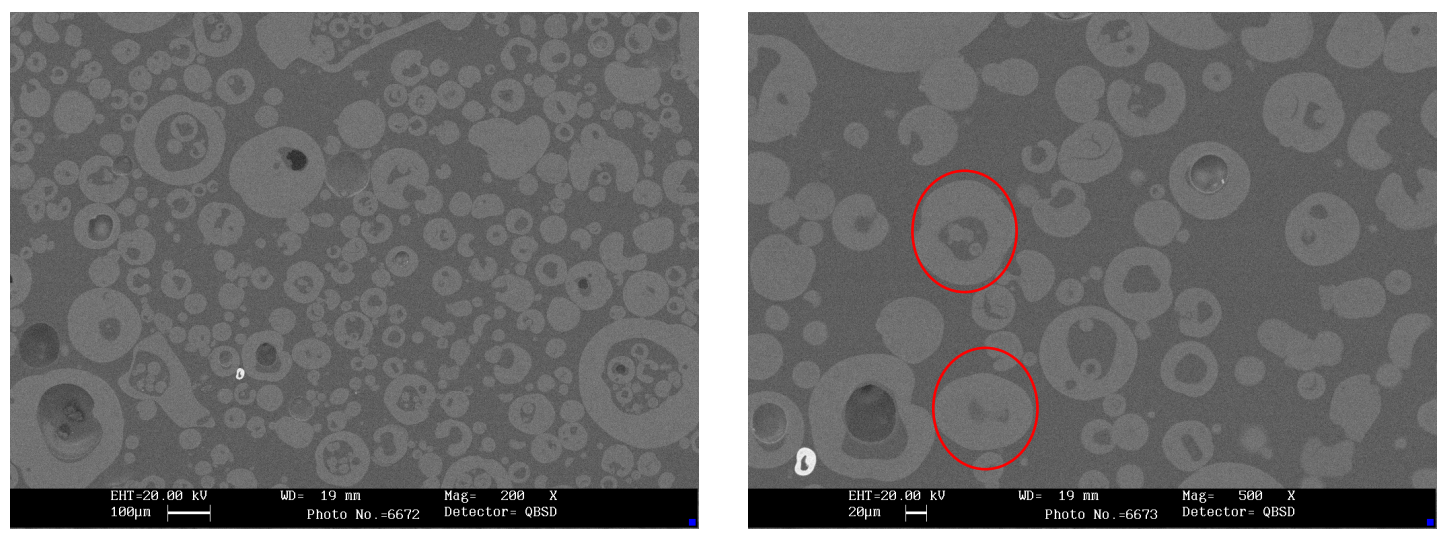

(b)
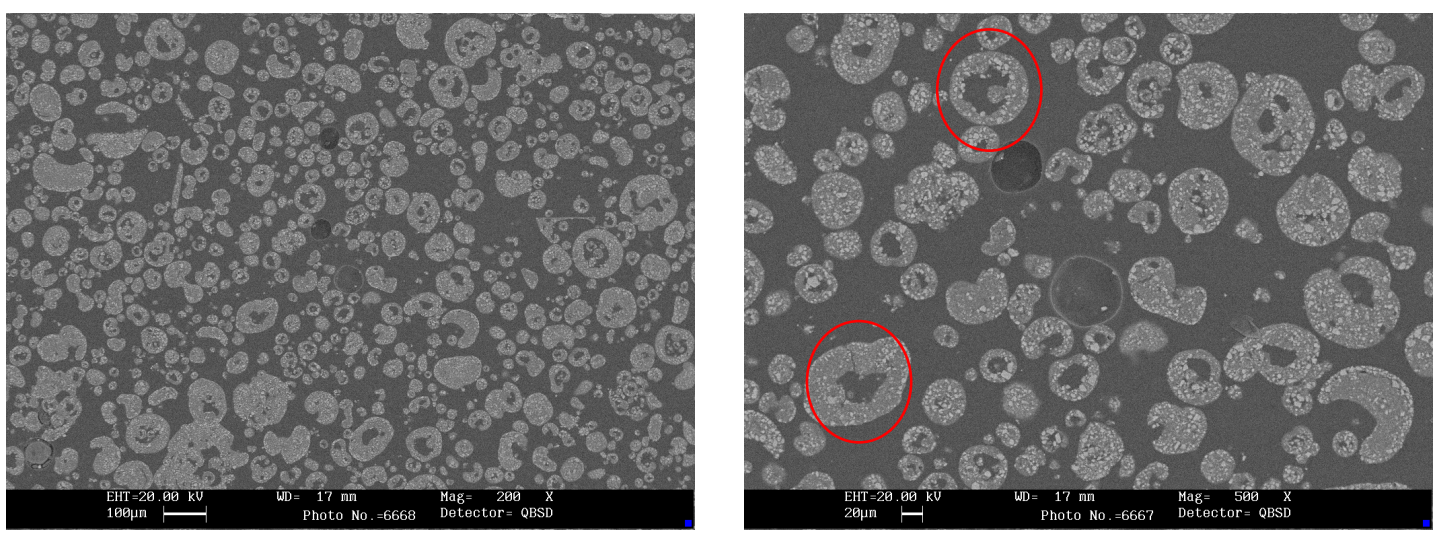

(c)

Figure 10. SEM micrographs of powders (a) $1, x_{C}=0, p H=10$, (b) $2, x_{C}=0, p H=2$ and (c) $3, x_{C}=0.85, p H=10$. 


\section{Table captions}

Table 1 . Viscosity of suspensions at $20 \% \mathrm{wt}$., $\mathrm{pH}=2$ at different coarse fraction.

Table 2. $b$ parameter depending on the coarse fraction and the initial droplet volume.

Table 3. Coarse and fine solid fraction, moisture content and particle size. 
Table 1. Viscosity of suspensions at $20 \% \mathrm{wt}$., $\mathrm{pH}=2$ at different coarse fraction.

\begin{tabular}{cc}
\hline $\begin{array}{c}\text { Coarse } \\
\text { fraction, } \boldsymbol{x}_{\boldsymbol{C}}\end{array}$ & $\begin{array}{c}\text { Viscosity, } \boldsymbol{\eta} \\
(\mathrm{Pa} \cdot \mathbf{s})\end{array}$ \\
\hline \hline $\mathbf{0}$ & 0.013 \\
\hline $\mathbf{0 . 4 0}$ & 0.006 \\
\hline $\mathbf{0 . 8 5}$ & 0.003 \\
\hline $\mathbf{1}$ & 0.004 \\
\hline \hline
\end{tabular}


Table 2. $b$ parameter depending on the coarse fraction and the initial droplet volume.

\begin{tabular}{cccc}
\multicolumn{5}{c}{ volume. } \\
\hline \multicolumn{5}{c}{ Coarse fraction, $\boldsymbol{x}_{\boldsymbol{C}}$} \\
\hline $\mathbf{0}$ & $\mathbf{0 . 4 0}$ & $\mathbf{0 . 8 5}$ & $\mathbf{1}$ \\
\hline 2.50 & 3.60 & 4.75 & 3.90 \\
\hline 2.75 & 2.95 & 3.10 & 2.95 \\
\hline
\end{tabular}


Table 3. Coarse and fine solid fraction, moisture content and particle size.

\begin{tabular}{cccccc} 
& $\begin{array}{c}\boldsymbol{w}_{C} \\
{[\%]}\end{array}$ & $\begin{array}{c}\boldsymbol{w}_{F} \\
{[\%]}\end{array}$ & $\begin{array}{c}\boldsymbol{X}_{C}[\mathrm{~kg} \text { water/kg } \\
\text { dry solid] }\end{array}$ & $\begin{array}{c}\boldsymbol{X}_{\boldsymbol{F}}[\mathrm{kg} \text { water } / \mathrm{kg} \\
\text { dry solid] }\end{array}$ & $\begin{array}{c}\boldsymbol{d}_{G, 50} \\
{[\boldsymbol{\mu m}]}\end{array}$ \\
\hline 1) $\boldsymbol{x}_{\boldsymbol{C}}=\mathbf{0}, \boldsymbol{p H}=\mathbf{1 0}$ & 52.5 & 47.5 & 0.245 & 0.029 & 105.40 \\
\hline 2) $\boldsymbol{x}_{\boldsymbol{C}}=\mathbf{0}, \boldsymbol{p H}=\mathbf{2}$ & 53.3 & 46.7 & 0.130 & 0.016 & 30.00 \\
\hline 3) $\boldsymbol{x}_{\boldsymbol{C}}=\mathbf{0 . 8 5}, \boldsymbol{p H}=\mathbf{1 0}$ & 31.0 & 69.0 & 0.027 & 0.005 & 12.88 \\
\hline \hline
\end{tabular}

